\title{
Sensory profile and acceptability of juices from mandarin varieties and hybrids
}

\author{
L. Carbonell, S. Bayarri, J. L. Navarro, I. Carbonell, L. Izquierdo* \\ Instituto de Agroquímica y Tecnología de Alimentos (IATA-CSIC). \\ P.O. Box 73, Burjassot, Valencia, Spain
}

Fresh juices from mandarin varieties, from hybrids and from blends of these raw materials were evaluated by 100 consumers to determine acceptability and by 10 trained panellists to quantify sensory attributes. Trained panellists found the juice from Clemenules richer in both mandarin and fresh flavour (odour and taste) whereas Nova juice presented minimum scores for these attributes. These aspects obviously affected the evaluation of acceptability by consumers, who preferred the juice from Clemenules (a Clementine variety) either alone or blended in major proportions with less preferred varieties such as Marisol, Hernandina (Clementines), Ortanique or Nova (hybrids). Nova juice was rejected by most consumers, but accepted by a small group of them. These results are of great importance for the European citrus industry since Clemenules is the most abundant variety and will constitute the main source of raw material for processing plants.

Key words: mandarin juice, sensory profile, acceptability, data analysis.

\section{$<1>$ INTRODUCTION}

In a previous paper (Carbonell et al., 2008a) a comparative study on acceptability of chilled mandarin and orange juices was performed by consumers from the area of Valencia (Spain), showing that mandarin juices were generally preferred. The interest of performing similar tests in other European countries was suggested since, in the case that the higher acceptability of mandarin juices were confirmed, its production at a large scale would be worth to be promoted. Southern Europe is among the main world mandarin producers (only surpassed by China) and its citrus plants, that presently produce mainly orange juices, can be adapted to mandarin juice production with minimal or no changes. From a European perspective, mandarin juice would be a product obtained from domestic crops prepared and consumed in Europe. This is not the case of orange juice, whose production is not governed by European countries.

Compared with orange juice, very little research has been carried out on mandarin juice. Its volatile composition mainly related with the constituents producing off-flavours due to heating process

\footnotetext{
* To whom correspondence should be sent (e-mail: luisiz@iata.csic.es)

Received: 23 April 2008; Revised: 4 August 2008
} 
has been analysed in some recent papers (Pérez-López and Carbonell-Barrachina, 2006; Pérez-López et al., 2006; Pérez-López et al., 2007) but almost no literature exists about the technology of mandarin juice production. A study of heat treatment conditions of chilled juices (Sentandreu et al., 2005) concluded that pasteurisation at $85^{\circ} \mathrm{C}$ for 10 seconds satisfactorily inactivate clarifying enzymes with minimal loss of acceptability. On the other hand, juices treated under these heat conditions presented the same acceptability as juices stabilised by pulsed electric fields (Sentandreu et al., 2006).

Carbonell et al. (2007) studied the sensory characteristics of mandarin juices, proposed a list of descriptors to perform profile analysis and trained a group of assessors for this purpose. This group evaluated commercial and experimental mandarin and orange juices as exposed in the paper mentioned at the beginning of this section (Carbonell et al., 2008a).

Other important technological aspects are the suitability of mandarin varieties to produce commercial juices and the study of juice blends to obtain highly acceptable and uniform products in the different productions during the year. Blends are mainly necessary since the relationship between total solids and acid contents increases as fruits ripen and only juices with a balanced relationship are accepted by consumers. These aspects have been considered with orange juices (Kimball, 1999; Berry and Veldhuis, 1977; Izquierdo et al., 1980) but not with mandarin juices.

The objective of this paper is to determine, in juices from different pure mandarin varieties and in juice blends, the intensity of sensory attributes, quantified by trained assessors, and the acceptability, evaluated by consumers.

\section{$<$ 1 $>$ MATERIAL AND METHODS}

\section{$<2>$ Fruits}

Three pure Clementine (Citrus clementina Hort. Ex Tan.) cultivars: Clemenules, Hernandine and Marisol and two hybrids: Nova (Clementine $\mathrm{x}$ tangelo Orlando) and Ortanique (Clementine $\mathrm{x}$ orange) were used as raw materials. Fruits were harvested from an orchard located at Lliria (Valencia, Spain).

\section{$<2>$ Juice extraction}

Fruits were squeezed in an industrial extractor with finger cups (model Exzel from TECMAFRU, El Puig, Valencia, Spain). The juice was passed through a finisher with $0.5 \mathrm{~mm}$ holes. Samples were immediately frozen and stored at $-20^{\circ} \mathrm{C}$ until analysed.

\section{$<2>$ Juice blends}

Juices of different Brix to acid ratios were used to obtain blends with a ratio value previously fixed. 


\section{$<3>$ Brix to acid ratio measurement}

Total soluble solids were measured as ${ }^{\circ}$ Brix with a R-X 1000 digital refractometer (Pal-1, Atago Co., LTD, Tokio). Total titratable acidity was assessed by titration with sodium hydroxide $(0.1 \mathrm{~N})$ and expressed as $\%$ citric acid.

\section{$<3>$ Blend proportions}

The composition of binary blends were determined according to the expression:

$$
R=\frac{B_{1} P_{1}+B_{2}\left(100-P_{1}\right)}{A_{1} P_{1}+A_{2}\left(100-P_{1}\right)}
$$

where $\mathrm{R}$ is the Brix to acid ratio desired in the blend. $\mathrm{B}_{1}, \mathrm{~A}_{1}$, and $\mathrm{P}_{1}$ are Brix, acidity, and percentage of one of the juices forming the blend. $\mathrm{B}_{2}$ and $\mathrm{A}_{2}$ are Brix and acidity of the other juice.

\section{$<2>$ Sensory analysis}

Tests were conducted in a standard room (ISO, 1988) equipped with 9 individual taste booths. Samples were thawed in water baths the day of testing and served at room temperature (about $20^{\circ} \mathrm{C}$ ) in cups labelled with random 3-digit codes. Water was provided to assist in cleansing the palate.

\section{$<3>$ Sensory profile}

The process of selection and training of the panellists who performed the sensory profiles described in this paper has been previously published (Carbonell et al., 2007). Basically, the attribute terms were generated by 20 panellists using the Repertory Grid method. From this group, 11 assessors were selected taking into account their previous experience in sensory profile. These 11 judges participate in discussion sessions to select the final list of attributes use to evaluate juices. The limits of the evaluation scales were fixed by consensus using juice samples with high or low intensities of different attributes (i.e. sweetness, acidity, bitterness). Mandarin and orange juices with different characteristics were prepared and profiled to evaluate the reproducibility, homogeneity and consistency of the assessors. According to the results, 10 of the 11 assessors were selected.

This group of 10 trained judges evaluated the intensity of 25 sensory attributes in the groups of samples specified in the section of Results. All juices were tested in duplicate and a maximum of three samples was evaluated in each session. Samples of each session were served in different order to the assessors. The judges evaluated attributes' intensity using unstructured scales from 0 to 10 with anchor terms (from not perceived or weak to intense in most of attributes, from lemon to orange-reddish in colour, from scarce to abundant in pulp attributes, and from unripe to overripe in maturity attributes). A Clemenules juice (Brix to acid ratio of 16.4 , pasteurised at $85{ }^{\circ} \mathrm{C}$ during $10 \mathrm{~s}$ and stored at $-20{ }^{\circ} \mathrm{C}$ until the date of each analysis session) was served as reference sample. The intensities of the attributes 
in the reference sample (consensus of previous discussions among test panel members) were indicated in the scales (Carbonell et al., 2007).

\section{$<3>$ Acceptability by consumers}

Two groups of 100 participants, randomly selected by the Association of Valencian Consumers and Users (AVACU) among their associates regular consumers of fruit juices, performed two evaluations of acceptability, one of juices from individual varieties and another one of blends, according to an hedonic scale from 1 to 9 . The juices included in each evaluation will be specified in the section of Results. Time delay between judgements of two consecutive samples was fixed at 30 seconds. Samples were served in different order to each assessor (McFie et al., 1989) according to a Williams balanced design (Compusense five v. 4.6, Compusense Inc., Guelph, Ontario, Canada).

\section{$<3>$ Sensory evaluation of Brix to acid ratio of juice blends}

Four Clementine juices with different Brix to acid ratios (harvested from the same trees in different dates) were evaluated by 50 non trained panellists of our institute who used ranking tests to order the samples according to the sensory perception of the level of maturity (increasing ratios) and according to acceptability.

\section{$<2>$ Data analysis}

Sensory data were acquired by using Compusense five v. 4.6, cited above. BMDP Statistical Software (University of California Press, Berkeley, USA, 1985) and PC-MDS Multidimensional Statistics Package (Brigham Young University, Provo, USA, 1990) were used to apply the following methods:

$<3>$ Univariate analysis of variance (ANOVA)

Two-way ANOVA was applied to data of each attribute obtained from sensory profile and to acceptability data from consumers tests. Differences between individual samples were analysed by Tukey's test (Winner, 1971).

\section{$<3>$ Friedman test}

This type of test (ISO, 2006; Meilgaard et al., 1999) was applied to data obtained from ranking tests (sensory evaluation of Brix to acid ratio of juice blends, see above) and to acceptability data. In this last case the acceptability scores (1 to 9) given by each consumer to the evaluated samples were converted into rank order numbers. Ties received equal fractional numbers. Differences between particular samples were analysed using Tukey's test. 
This technique (BMDP Statistical Software) was applied to select the group of sensory attributes showing maximum capacity of discrimination among profiled samples. Representations were obtained by Canonical Analysis of the sensory data corresponding to the selected group of attributes.

\section{$<3>$ Segmentation of consumers}

The method used for consumers' segmentation (Carbonell et al., 2008b) basically consists in computing the correlation coefficients between the acceptability scores given by each consumer to the samples and the average intensity scores for each attribute in the same samples. A rectangular matrix "consumers x attributes" is thus obtained to which Clustering Ward method (PC-MDS package) is applied. In this way, groups of consumers differing in their preferences were obtained and the differences were related with the intensity of sensory attributes.

\section{$<1>$ RESULTS AND DISCUSSION}

\section{$<2>$ Juices from individual varieties and hybrids}

Table 1 shows harvesting dates, Brix, acidity, and Brix to acid ratios of the varieties analysed in this section. Harvesting dates were within the usual period for fresh fruit marketing of these varieties, although ratios can greatly vary during the whole period and between growing areas. As it can be observed in Table 1, ratios also varied between analysed samples which undoubtedly must affect their acceptability that is discussed below. Nevertheless, it has been considered adequate to compare the acceptability of juices from different varieties at their usual harvesting dates.

\section{$<3>$ Sensory profile}

Individual analysis by attribute.- Table 2 summarizes the results from two-way ANOVA applied to profile data produced by trained panellists who quantified the intensity of sensory attributes in the juices from the studied varieties and hybrids. Samples were considered as a fixed effect and assessors as a random effect. The table lists, for each attribute, the error and the interaction (panellists $\mathrm{x}$ samples) mean squares as well as the experimental $\mathrm{F}$ values (with their probabilities) for the effects "panellists" and "samples" and for the interaction. Although the F values corresponding to panellists and to the interaction were significant ( $95 \%$ level, probability lower than 0.05 ) in several cases, they were generally much lower than the $\mathrm{F}$ value of samples, what allows to centre the discussion in this effect, the most interesting one. With the exceptions of turbidity, pulp (aspect and texture) and body, great differences among samples were found for all attributes, as the $\mathrm{F}$ values and their probabilities indicate. Main differences among juices will be discussed with the help of Table 3 which shows, for each attribute, the mean intensity score per sample and the values of the minimum significant 
difference (Tukey's test, confidence level of $95 \%$ ) between mean scores. These values will allow analysing differences since marks indicating which particular samples differ from each other have been avoided to simplify the table. Colour was the attribute presenting maximum differences ( $F=117.9$, Table 2). All samples significantly differed from each other for this attribute except Clemenules and Marisol (Table 3). Also important differences were found in orange odour and in orange taste, for which Ortanique, a hybrid of orange and mandarin, showed significantly higher mean scores. In maturity taste, Hernandina and Marisol received maximum and minimum mean scores respectively. This is closely related with Brix to acid ratio, maximum in the first variety and minimum in the second one. Accordingly, Marisol and Ortanique (with the lowest Brix to acid ratios) were scored as significantly higher in acidity than the other varieties, whereas the mean score in sweetness of Hernandina, variety that showed the maximum Brix to acid ratio, was significantly higher than those of the other juices.

Finally, the juice from Nova showed significantly (95\% level) lower mean scores for mandarin odour, fresh odour and their homonymous attributes of taste whereas Clemenules juice presented maximum or almost maximum scores for these attributes, although without significant differences with the other juices except with Nova. On the contrary, Nova had significantly more intense off odour and off taste, for which Clemenules showed minimum scores.

Combined analysis of attributes.- For an overall view of the differences among juices from individual varieties (and for comparative purposes with the results with blended samples shown in the next section) a selection of the attributes showing maximum power of discrimination among samples was carried out using Stepwise Discriminant Analysis applied to profile data of attributes of odour (7) and taste (12) exclusively. To simplify the analysis the intensity scores (for each attribute and sample) from all assessors and repetitions were pooled and considered as random data from a normal population.

The attributes that better discriminate among juices from individual varieties and hybrids were orange odour, mandarin taste, fresh odour, bitterness, off odour and odour intensity, in decreasing order of discriminant power. Figure 1 shows the representation of samples according to the first two axes obtained from Canonical Analysis applied to the data of these 6 attributes. The confidence regions (level $95 \%$ ) of the centroids are also indicated in Figure 1, showing a clear separation between varieties. The F values associated with Mahalanobis' distances between centroids had probabilities lower than 0.05 for all possible pairs of centroids.

\section{$<3>$ Acceptability by consumers}

Global results.- Figure 2 shows the frequencies of the hedonic acceptability scores (1 to 9) given by 100 consumers to the samples of fresh juices of each variety. Figure 2 also shows the Chi- 
square statistics and their probabilities obtained by applying the test from Pearson to compare the observed frequencies with those expected assuming a normal distribution of scores. Only the distribution of frequencies from Marisol and Nova with probabilities higher than 0.05 could be considered as roughly normal. Moreover, two modes were clearly observed in data from Ortanique, Hernandina and also from Nova. In all these varieties the first mode appeared in the area of the scale corresponding to sample rejection (lower than 5 in the hedonic scale) and the second one in the area of acceptation. Thus, the observed score frequencies for these varieties suggest a mixture of two normal distributions or, in other words, that the group of 100 consumers cannot be considered as representative of an homogeneous population but from two different populations, one who likes the sample and another one who dislikes it. Villanueva et al. (2000; 2005) also observed lack of normality in data from hedonic scales and suggested that ANOVA is not fully suitable in these conditions. These authors tested hybrid hedonic, self-adjusting and ranking scales as alternatives. This last approach was used in our previous paper on commercial and experimental mandarin juices (Carbonell et al., 2008b). Hedonic data were converted in ordered data by assigning rank order numbers to the scores given by each consumer to the samples evaluated and the results were analysed using Friedman and Tukey tests. The same procedure has been applied in this work. The results for fresh juices from pure varieties are shown in Table 4, where the obtained rank sums and the significance ( $95 \%$ level) of the differences between rank sums are indicated. The juice from Clemenules (Clementine) was the most preferred, with a rank sum significantly higher than those of the other samples. The higher acceptability of Clemenules is important for the citrus industry since this variety is, by far, the most abundant and may constitute the core of juice production. On the contrary, the juice from the hybrid Nova was the least preferred, with significant differences in relation to all other samples except Marisol. This last variety did not significantly differ from Ortanique and Hernandina.

Segmentation of consumers.- Global results discussed above inform about general tendencies but not about groups of consumers with differences in preferences. In an attempt to identify these groups a segmentation procedure based on clustering the consumers according with their correlation coefficients with the attributes (Carbonell et al., 2008b) was applied and a solution with four segments was selected. Table 5 shows the mean acceptability scores of the samples for each segment. Chisquared (Pearson) tests showed distributions of score frequencies compatible with the normal law ( $p>0.05$ ). Thus, two-way (samples and consumers) ANOVA was applied to data from each segment and Tukey's test was used to analyse the significance of the differences between particular samples, shown as superscripts in the table.

According to these results it can be concluded that segmentation gave additional information not available from global results. For instance, the least preferred juice, Nova, was rejected by 75 of consumers, those forming segments 1,3 , and 4, but clearly accepted by the remaining 25 (segment 2), 
showing a small but not negligible part of the population that like the peculiar flavour (see the profile results discussed above) of this hybrid. On the other hand, Clemenules received the highest mean scores in the same 3 segments that rejected Nova and the second maximum score in the other segment, which is reflected in the global results discussed above by a first position of the juice from Clemenules. As it was also mentioned, Ortanique, Hernandina and Marisol, did not differ from each other. The results of the segmentation process (Table 5) show that Ortanique was well accepted by segment 4 , Hernandina by segment 3 and Marisol by segment 1 . In the remaining segments each one of these varieties were scarcely accepted or even rejected.

\section{$<2>$ Blended juices}

Blends are necessary to make uniform the characteristics of the commercial juices obtained in different periods of the year. Brix to acid ratio is, probably, the most important characteristic, since the acceptability by consumers strongly depends on the equilibrium between solid contents (mainly sugars) and acidity (Izquierdo, 1994). Thus, the proportion of juices to be blended was computed in this work to obtain a previously established ratio, which was estimated by acceptability tests among juices with different ratios.

\section{$<3>$ Estimation of a suitable Brix to acid ratio of blends}

Table 6 shows Brix to acid ratios of four Clementine juices which were evaluated by 50 assessors. The evaluations were performed according to two criteria: ranking the samples according to the sensory perception of their ratios (from low to high) and ranking them according to acceptability. Ranking tests were applied to these evaluations. As indicated in Table 6, the lowest two ratios, 12.4 and 13.8, were ranked in reverse order but without significant differences between them at the $95 \%$ level. The two highest ratios, 16.4 and 21.3, ranked in this order by the assessors, were significantly distinguished from each other and both from the lowest ratios. Concerning acceptability, the juice with a Brix to acid ratio of 16.4 was significantly preferred to the other juices, which did not differ from each other. This means that acceptability decreases when the juices present either low or high Brix to acid ratios. The optimum ratio, according to these results, has been estimated around 16, and blend proportions were computed according to this value.

\section{$<3>$ Blend proportions}

Table 7 lists Brix, acidity and Brix to acid ratios of the juices from pure varieties used to prepare 6 blends with a uniform Brix to acid ratio of 16. Subscripts " $r$ " and "g" mean "ripe" and "green" respectively and indicate that the ratio was above or below 16 . The blends prepared with these juices from pure varieties are listed in Table 8 as well as the proportions of the first component of the blend. The first four blends included major proportions of ripe Clemenules whereas the $5^{\text {th }}$ blend had a minor proportion of green Clemenules and the $6^{\text {th }}$ blend did not include this variety but the other two 
clementine varieties. Observe that the third blend was constituted by only Clemenules, ripe and green. Table 8 also shows the Brix to acid ratio of two pure juices from Hernandina and Nova included for comparison purposes. Juices from Marisol and Ortanique were not included since samples with Brix to acid ratios reasonably close to 16 were not available.

\section{$<3>$ Sensory profile}

Individual analysis by attribute.- Table 9 summarises the results of ANOVA applied to profile data quantified in the blends commented above and in the juices from Hernandina and Nova (Table 8). The effect "panellists" and the interaction "panellists x samples", were, although significant in some cases, much lower than the effect "samples". To simplify Table 9 only F values and probabilities of this last effect have been listed. These F values were, in general, lower than those corresponding to the same effect in juices from individual varieties (Table 2), a logical consequence of the larger uniformity of blends. Table 10 shows the mean values for each attribute and the minimum significant differences (95\% level) according to Tukey's test. For many attributes the differences were only significant between Nova and all or several of the remaining juices. This happened, for instance, with browning, mandarin odour, maturity odour, off odour, maturity taste, acidity, and off taste. In fresh odour, mandarin taste and fresh taste the sample constituted exclusively by Clemenules $\left(\mathrm{C}_{\mathrm{r}}+\mathrm{C}_{\mathrm{g}}\right)$ received the maximum mean score, significantly higher than the scores of some or all other samples.

Combined analysis of attributes.- The group of odour and taste attributes with maximum discrimination among samples was formed (according to Stepwise Discriminant Analysis results) by sweetness, odour intensity, bitterness, fresh taste, peel oil odour and astringency, in decreasing order of discriminant power. Figure 3 shows the representation of samples in the map of the first two dimensions obtained by Canonical Analysis applied to data of these attributes. To simplify the figure, confidence regions (95\% level) have been represented individually only for Hernandina and Nova whereas blends have been included in a unique region. In agreement with the uniformity of the blends, the corresponding representations were close whereas Nova and Hernandina appeared far from the blends.

\section{$<1>$ Acceptability by consumers}

Global results.- Figure 4 shows the distribution of frequencies of acceptability scores of the six blends and of the two juices from Hernandina and Nova. As it was discussed above for the juices from pure varieties, lack of normality was observed for most samples and, thus, acceptability data were converted into rank order numbers and analysed by Tukey test with the results summarised in Table 11. Rank sums from $\mathrm{C}_{\mathrm{r}}+\mathrm{O}_{\mathrm{g}}$ to $\mathrm{M}_{\mathrm{g}}+\mathrm{H}_{\mathrm{r}}$ decreased slowly and almost linearly but an abrupt 
decrease was observed for Nova, confirming the low acceptability of this juice, as mentioned in the previous section. An important aspect is that the four samples including major proportions of ripe Clemenules $\left(\mathrm{C}_{\mathrm{r}}\right)$ were ordered in the first positions, without significant differences among them. Thus, Clemenules can be considered very suitable to prepare commercial juices not only alone but in blends (in major proportions) with other less accepted varieties. On the contrary, when Clemenules was in a minor proportion $\left(\mathrm{C}_{\mathrm{g}}+\mathrm{H}_{\mathrm{r}}\right)$ or not present $\left(\mathrm{M}_{\mathrm{g}}+\mathrm{H}_{\mathrm{r}}\right)$ the rank sums were significantly lower and similar to that of Hernandina $(\mathrm{H})$. The rank sum of the juice from Nova $(\mathrm{N})$ was significantly lower than all others.

Segmentation of consumers.- By clustering the matrix of correlation coefficients between consumers and attributes and selecting a solution with four clusters, the results shown in Table 12 were obtained. ANOVA was applied to data from each segment and differences between means of particular samples were analysed by Tukey's test. The table indicates as superscripts the significance of individual differences between mean scores. In general, and also as a consequence of the uniformity of the blends commented above, the differences between segments and within segments were lower than those discussed in Table 5 for juices from individual varieties. All groups gave maximum or almost maximum acceptability scores to the blends including ripe Clemenules and the main differences between groups were due to the scores given to the remaining samples. For instance, Nova was accepted by a small group (segment 4,17 consumers) but rejected by the rest of consumers, confirming the results discussed above, and Hernandina received maximum acceptability scores in the group constituting segment 1 . Thus, these results confirm that the mandarin Clemenules, which is the most abundant, is also the variety that produces the best juice, either when used as unique raw material or when blended in major proportions with other varieties less suitable for producing high quality juices.

\section{$<$ 1>ACKNOWLEDGEMENTS}

This work is part of the Project AGL 2006-05809/ALI financed by Ministerio de Educación y Ciencia (Spain). Authors thank to CSIC (Program I3P, granted by European Social Funds) for Sara Bayarri contract and to Generalitat Valenciana, Conselleria d' Agricultura, Pesca i Alimentació (AGROALIMED) for additional financial support.

\section{$<1>$ REFERENCES}

Berry R.E. and Veldhuis M.K. (1977). Processing of oranges, grapefruit and tangerines. In Nagy S., Shaw P.E. and Veldhuis M.K. (eds), Citrus Science and Technology-2. Westport (Connecticut): The Avi Publishing Company, Inc., pp. 177-252. 
Carbonell L., Izquierdo L. and Carbonell I. (2007). Sensory analysis of Spanish mandarin juices. Selection of attributes and panel performance. Food Quality and Preference 18: 329-341.

Carbonell L., Navarro J. L., Izquierdo L. and Carbonell I. (2008a). Sensory profile of mandarin chilled juices and consumers' acceptability. Food Science and Technology International 14: 157-166.

Carbonell L., Izquierdo L., Carbonell I. and Costell E. (2008b). Segmentation of food consumers according to sensory attributes projected on preference spaces. Food Quality and Preference 19: 7178.

ISO (1988). General guidance for the design of test room. Standard no 8589. Geneva. Switzerland.

ISO (2006). Sensory Analysis. Methodology. Ranking. Standard no 8587. Geneva. Switzerland.

Izquierdo L. (1994). Quality factors of orange juice. Symposium "Health and Orange". Fundación Valenciana de Estudios Avanzados. November.

Izquierdo L., Gasque F., Nieto P. and Lafuente B. (1980). Zumo de naranja refrigerado. IV. Preparación de zumo de calidad uniforme a lo largo del año. Revista de Agroquímica y Tecnología de Alimentos 20: 525-530.

Kimball D. A. (1999). Citrus Processing. A Complete Guide (2nd ed). New York: Kluwer Academic/Plenum Publishers.

McFie H.J.H., Bratchell N., Greenhoff K. and Vallis L.V. (1989). Designs to balance the effect of order of presentation and first-order carry-over effects in hall tests. Journal of Sensory Studies 4: 129148.

Meilgaard M., Civille G.V. and Carr B.T. (1999). Sensory Evaluation Techniques (3rd ed). Boca Raton, Florida: CRC Press LLC, pp. 387.

Pérez-López A. J. and Carbonell-Barrachina A.A. (2006). Volatile odour components and sensory quality of fresh and processed mandarin juices. Journal of the Science of Food and Agriculture 86: 2404-2411.

Pérez-López A. J., López-Nicolás J.M. and Carbonell-Barrachina A.A. (2007). Effects of organic farming on minerals contents and aroma composition of Clemenules mandarin juice. European Food Research and Technology 225: 255-260.

Pérez-López A. J., Saura D., Lorente J. and Carbonell-Barrachina A.A. (2006). Limonene, linalool, $\alpha$ terpineol, and terpinen-4-ol as quality control parameters in mandarin juice processing. European Food Research and Technology 222: 281-285.

Sentandreu E., Carbonell L., Carbonell J.V. and Izquierdo L. (2005). Effects of heat treatment conditions on fresh taste and on pectinmethylesterase activity of chilled mandarin and orange juices. Food Science and Technology International 11: 217-222.

Sentandreu E., Carbonell L., Rodrigo D. and Carbonell J.V. (2006). Pulse electric-fields versus thermal treatment, Equivalent processes to obtain equally acceptable citrus juices. Journal of Food Protection 69: 2016-2018.

Villanueva N.D.M., Petenate A.J. and Da Silva M.A.A.P. (2005). Performance of the hybrid hedonic scale as compared to the traditional hedonic, self-adjusting and ranking scales. Food Quality and Preference 16: 691-703.

Villanueva N.D.M., Petenate A.J. and Da Silva M.A.A.P. (2000). Performance of three affective methods and diagnosis of the ANOVA model. Food Quality and Preference 11: 363-370.

Winner B.J. (1971). Statistical Principles in Experimental Design (2nd ed). New York: McGraw-Hill Book Company Inc. 
Table 1. Brix to acid ratios and harvesting dates of fresh juices.

\begin{tabular}{lcccc}
\hline Variety & Brix & Acidity & $\begin{array}{c}\text { Brix to acid } \\
\text { ratio }\end{array}$ & $\begin{array}{c}\text { Harvesting } \\
\text { dates }\end{array}$ \\
\hline $\begin{array}{l}\text { C: Clemenules } \\
\text { (Clementine) }\end{array}$ & 11.5 & 0.93 & 12.4 & $2004 / 12 / 15$ \\
$\begin{array}{l}\text { O: Ortanique } \\
\text { (Hybrid) }\end{array}$ & 13.3 & 1.31 & 10.2 & $2005 / 04 / 27$ \\
$\begin{array}{l}\text { H: Hernandina } \\
\text { (Clementine) }\end{array}$ & 12.5 & 0.74 & 16.9 & $2005 / 01 / 12$ \\
$\begin{array}{l}\text { M: Marisol } \\
\text { (Clementine) }\end{array}$ & 10.1 & 1.19 & 8.5 & $2004 / 11 / 18$ \\
$\begin{array}{l}\text { N: Nova } \\
\text { (Hybrid) }\end{array}$ & 12.6 & 0.91 & 13.8 & $2005 / 01 / 12$ \\
\hline
\end{tabular}


Table 2. Descriptive profile of juices from individual varieties. Summary results of ANOVA by attribute

\begin{tabular}{|c|c|c|c|c|c|c|c|c|c|}
\hline \multirow{3}{*}{\multicolumn{2}{|c|}{ ATTRIBUTE }} & \multirow{3}{*}{$\begin{array}{l}\text { Error } \\
\text { mean } \\
\text { square }\end{array}$} & \multirow{3}{*}{$\begin{array}{c}\text { Interaction } \\
\text { mean } \\
\text { square }\end{array}$} & \multicolumn{6}{|c|}{ Experimental $\mathrm{F}$ values and probabilities } \\
\hline & & & & \multicolumn{2}{|c|}{ Assessors } & \multicolumn{2}{|c|}{$\underline{\text { Samples }}$} & \multicolumn{2}{|c|}{ Interaction } \\
\hline & & & & $F$ & $p$ & $F$ & $p$ & $F$ & $p$ \\
\hline & ASPECT & & & & & & & & \\
\hline 1 & Colour & 0.37 & 0.65 & 0.39 & 0.93 & 117.9 & $<0.01$ & 1.77 & 0.01 \\
\hline 2 & Browning & 0.10 & 0.11 & 2.03 & 0.06 & 3.67 & 0.01 & 1.15 & 0.29 \\
\hline 3 & Turbidity & 0.21 & 0.17 & 1.02 & 0.44 & 1.42 & 0.25 & 0.83 & 0.73 \\
\hline 4 & $\begin{array}{l}\text { Pulp } \\
\text { ODOUR }\end{array}$ & 0.31 & 0.53 & 1.41 & 0.22 & 0.72 & 0.58 & 1.73 & 0.02 \\
\hline 5 & Odour intensity & 1.52 & 0.59 & 2.29 & 0.04 & 10.0 & $<0.01$ & 0.39 & 1.00 \\
\hline 6 & Mandarin odour & 1.08 & 04 & 0.42 & 0.92 & 9.28 & $<0.01$ & 0.96 & 0.53 \\
\hline 7 & Orange odour & 0.35 & 0.51 & 1.73 & 0.12 & 15.75 & $<0.01$ & 1.47 & 0.07 \\
\hline 8 & Maturity odour & 1.03 & 69 & 0.70 & 0.7 & 6.53 & $<0.01$ & 0.67 & 0.91 \\
\hline 9 & Fresh odour & 1.62 & 1. & 2.53 & 0.02 & 13.72 & $<0.01$ & 1.03 & 0.44 \\
\hline 10 & Peel oil odour & 0.34 & 0.32 & 1.93 & 0.08 & 3.25 & 0.02 & 0.95 & 0.55 \\
\hline 11 & $\begin{array}{l}\text { Off odour } \\
\text { TASTE }\end{array}$ & 0.98 & 1.05 & 4.54 & $<0.01$ & 7.9 & $<0.01$ & 1.08 & 0.38 \\
\hline 12 & Taste intensity & 1.07 & 1.74 & 0.87 & 0.56 & 3.78 & 0.01 & 1.63 & 0.03 \\
\hline 13 & Mandarin taste & 0.98 & 1.41 & 3.48 & $<0.01$ & 4.65 & $<0.01$ & 1.45 & 0.08 \\
\hline 14 & Orange taste & 0.58 & 5 & 1.37 & 0.24 & 8.6 & $<0.01$ & 1.81 & 0.01 \\
\hline 15 & Maturity taste & 1.15 & 1.55 & 1.01 & 0.45 & 12.48 & $<0.01$ & 1.35 & 0.12 \\
\hline 16 & Fresh taste & 1.34 & 1.90 & 4.00 & $<0.01$ & 9.89 & $<0.01$ & 1.41 & 0.09 \\
\hline 17 & Acidity & 1.60 & 2.13 & 0.11 & 1.00 & 8.42 & $<0.01$ & 1.33 & 0.13 \\
\hline 18 & Sweetness & 0.91 & 1.23 & 0.87 & 0.56 & 13.22 & $<0.01$ & 1.36 & 0.12 \\
\hline 19 & Bitterness & 0.65 & 0.80 & 2.21 & 0.04 & 10.24 & $<0.01$ & 1.23 & 0.21 \\
\hline 20 & Peel oil taste & 0.58 & 1.37 & 1.22 & 0.31 & 5.35 & $<0.01$ & 2.34 & $<0.01$ \\
\hline 21 & Astringency & 0.64 & 1.60 & 2.08 & 0.06 & 4.98 & $<0.01$ & 2.49 & $<0.01$ \\
\hline 22 & Off taste & 0.97 & 1.50 & 4.23 & $<0.01$ & 6.08 & $<0.01$ & 1.55 & 0.05 \\
\hline 23 & $\begin{array}{l}\text { Persistent taste } \\
\text { TEXTURE }\end{array}$ & 0.97 & 1.07 & 2.82 & 0.01 & 12 & $<0.01$ & 1.09 & 0.35 \\
\hline 24 & Pulp & 0.1 & 0.21 & 1.81 & 0.10 & 0.74 & 0.57 & 1.88 & 0.01 \\
\hline 25 & Body & 0.45 & 0.50 & 0.88 & 0.55 & 0.85 & 0.51 & 1.12 & 0.32 \\
\hline
\end{tabular}


Table 3. Sensory profile of juices from individual varieties. Mean intensity scores of attributes and minimum significant differences (MSD) between means (Tukey's test, level $95 \%)$.

\begin{tabular}{|c|c|c|c|c|c|c|c|}
\hline & \multirow[t]{2}{*}{ ATRIBUTTE } & \multicolumn{5}{|c|}{ Mean intensity scores } & \multirow[b]{2}{*}{ MSD } \\
\hline & & Clemenules & Marisol & Hernandina & Ortanique & Nova & \\
\hline & ASPECT & & & & & & \\
\hline 1 & Colour & 3.6 & 3.5 & 6.8 & 5.6 & 8.0 & 0.72 \\
\hline 2 & Browning & 1.1 & 1.0 & 1.2 & 1.4 & 1.3 & 0.30 \\
\hline 3 & Turbidity & 7.5 & 7.4 & 7.6 & 7.6 & 7.5 & 0.37 \\
\hline 4 & $\begin{array}{l}\text { Pulp } \\
\text { ODOUR }\end{array}$ & 3.4 & 3.4 & 3.4 & 3.2 & 3.1 & 0.65 \\
\hline 5 & Odour intensity & 4.6 & 4.8 & 5.4 & 5.6 & 5.9 & 0.69 \\
\hline 6 & Mandarin odour & 5.6 & 5.8 & 5.6 & 5.0 & 4.1 & 0.91 \\
\hline 7 & Orange odour & 1.9 & 1.9 & 1.6 & 3.0 & 1.4 & 0.64 \\
\hline 8 & Maturity odour & 4.2 & 3.9 & 4.9 & 4.9 & 4.9 & 0.74 \\
\hline 9 & Fresh odour & 5.9 & 5.7 & 5.5 & 5.1 & 3.2 & 1.15 \\
\hline 10 & Peel oil odour & 1.9 & 2.2 & 1.6 & 1.9 & 1.7 & 0.51 \\
\hline 11 & $\begin{array}{l}\text { Off odour } \\
\text { TASTE }\end{array}$ & 0.2 & 0.3 & 0.7 & 1.0 & 1.8 & 0.92 \\
\hline 12 & Taste intensity & 5.7 & 6.2 & 5.3 & 6.6 & 6.6 & 1.18 \\
\hline 13 & Mandarin taste & 5.8 & 5.1 & 5.4 & 5.5 & 4.3 & 1.06 \\
\hline 14 & Orange taste & 1.9 & 2.1 & 1.6 & 3.2 & 1.6 & 0.92 \\
\hline 15 & Maturity taste & 4.9 & 3.5 & 6.2 & 4.7 & 5.4 & 1.11 \\
\hline 16 & Fresh taste & 5.1 & 4.5 & 4.7 & 5.2 & 2.8 & 1.23 \\
\hline 17 & Acidity & 5.7 & 6.7 & 4.2 & 6.4 & 5.6 & 1.30 \\
\hline 18 & Sweetness & 4.8 & 3.3 & 5.8 & 4.4 & 4.5 & 0.99 \\
\hline 19 & Bitterness & 1.5 & 2.8 & 1.5 & 1.2 & 2.1 & 0.80 \\
\hline 20 & Peel oil taste & 2.4 & 3.6 & 2.0 & 2.6 & 2.2 & 1.05 \\
\hline 21 & Astringency & 1.9 & 3.2 & 1.6 & 2.6 & 2.1 & 1.13 \\
\hline 22 & Off taste & 0.3 & 0.9 & 0.8 & 0.7 & 2.1 & 1.10 \\
\hline 23 & $\begin{array}{l}\text { Persistent taste } \\
\text { TEXTURE }\end{array}$ & 4.3 & 5.9 & 4.0 & 5.5 & 5.1 & 0.92 \\
\hline 24 & Pulp & 1.6 & 1.8 & 1.6 & 1.7 & 1.7 & 0.41 \\
\hline 25 & Body & 4.9 & 5.0 & 5.0 & 5.3 & 5.1 & 0.64 \\
\hline
\end{tabular}


L. Carbonell et al.

Table 4. Acceptability data converted in rank order numbers: rank sums.

\begin{tabular}{lc}
\hline Samples & Rank sums \\
\hline Clemenules & $401.5^{\mathrm{a}}$ \\
Ortanique & $307.0^{\mathrm{b}}$ \\
Hernandina & $294.0^{\mathrm{b}}$ \\
Marisol & $263.0^{\mathrm{b}, \mathrm{c}}$ \\
Nova & $234.5^{\mathrm{c}}$ \\
\hline
\end{tabular}

Values followed by different superscript are statistically different (95\% level Tukey's test). 
Table 5. Mean acceptability scores by consumers' segments obtained from correlations between consumers and attributes of data of juices from individual varieties. Significance (95\% level) of the differences between means according to Tukey's test

\begin{tabular}{lcccc}
\hline Juices & $\begin{array}{c}\text { Quadrant 1 } \\
(32 \text { consumers })\end{array}$ & $\begin{array}{c}\text { Quadrant 2 } \\
(25 \text { consumers })\end{array}$ & $\begin{array}{c}\text { Quadrant 3 } \\
(21 \text { consumers })\end{array}$ & $\begin{array}{c}\text { Quadrant 4 } \\
(22 \text { consumers })\end{array}$ \\
\hline Clemenules & $6.6^{\mathrm{a}}$ & $6.0^{\mathrm{a}, \mathrm{b}}$ & $7.2^{\mathrm{a}}$ & $7.2^{\mathrm{a}}$ \\
Ortanique & $5.1^{\mathrm{b}}$ & $4.1^{\mathrm{c}}$ & $4.4^{\mathrm{b}}$ & $6.3^{\mathrm{a}, \mathrm{b}}$ \\
Hernandina & $4.0^{\mathrm{c}}$ & $5.5^{\mathrm{b}}$ & $6.7^{\mathrm{a}}$ & $5.7^{\mathrm{b}}$ \\
Marisol & $6.7^{\mathrm{a}}$ & $5.6^{\mathrm{b}}$ & $5.1^{\mathrm{b}}$ & $3.8^{\mathrm{c}}$ \\
Nova & $3.3^{\mathrm{c}}$ & $6.8^{\mathrm{a}}$ & $4.9^{\mathrm{b}}$ & $2.9^{\mathrm{c}}$ \\
\hline
\end{tabular}

Values within a column followed by different superscript are statistically different (95\% level Tukey's test). 
L. Carbonell et al.

Table 6. Clementine juices with different Brix to acid ratios ranked by 50 assessors according to sensory perception of the ratios and to acceptability: rank sums.

\begin{tabular}{ccrc}
\hline Samples & $\begin{array}{c}\text { Brix to acid } \\
\text { ratios }\end{array}$ & \multicolumn{2}{c}{ Rank sums $^{\mathrm{b}}$} \\
Perception & Acceptability \\
\hline C1 & 12.4 & $87^{\mathrm{a}}$ & $103^{\mathrm{a}}$ \\
C2 & 13.8 & $74^{\mathrm{a}}$ & $106^{\mathrm{a}}$ \\
C3 & 16.4 & $131^{\mathrm{b}}$ & $146^{\mathrm{b}}$ \\
$\mathrm{C} 4$ & 21.3 & $158^{\mathrm{c}}$ & $95^{\mathrm{a}}$ \\
\hline
\end{tabular}

Values within a column followed by different superscript are statistically different ( $95 \%$ level Tukey's test). 
Table 7. Brix, acidity and Brix to acid ratios of juices used to prepare blends.

\begin{tabular}{lcccc}
\hline Juice & Code $^{\mathrm{a}}$ & Brix & Acidity & $\begin{array}{c}\text { Brix to acid } \\
\text { ratio }\end{array}$ \\
\hline Clemenules ripe & $\mathrm{C}_{\mathrm{r}}$ & 12.3 & 0.60 & 21.1 \\
Clemenules green & $\mathrm{C}_{\mathrm{g}}$ & 10.2 & 1.18 & 8.6 \\
Marisol & $\mathrm{M}_{\mathrm{g}}$ & 11.2 & 1.41 & 7.9 \\
Ortanique & $\mathrm{O}_{\mathrm{g}}$ & 14.0 & 1.68 & 8.3 \\
Nova & $\mathrm{N}_{\mathrm{g}}$ & 12.2 & 1.20 & 10.2 \\
Hernandina & $\mathrm{H}_{\mathrm{r}}$ & 14.1 & 0.57 & 24.7 \\
\hline
\end{tabular}

"Subscripts "r" and "g" mean "ripe" and "green" respectively and indicate that the corresponding Brix to acid ratio is over or below 16 . 
Table 8. Samples (blends ${ }^{a}$ and pure juices ${ }^{b}$ ) used to analyse the attributes and the acceptability of blends

\begin{tabular}{lcc}
\hline Sample & $\begin{array}{c}\text { \% of the first } \\
\text { component }^{\mathrm{c}}\end{array}$ & $\begin{array}{c}\text { Brix to acid ratio } \\
\text { of pure juices }^{\text {com }}\end{array}$ \\
\hline $\mathrm{C}_{\mathrm{r}}+\mathrm{O}_{\mathrm{g}}$ & 83 & - \\
$\mathrm{C}_{\mathrm{r}}+\mathrm{N}_{\mathrm{g}}$ & 72 & - \\
$\mathrm{C}_{\mathrm{r}}+\mathrm{C}_{\mathrm{g}}$ & 76 & - \\
$\mathrm{C}_{\mathrm{r}}+\mathrm{M}_{\mathrm{g}}$ & 80 & - \\
$\mathrm{C}_{\mathrm{g}}+\mathrm{H}_{\mathrm{r}}$ & 37 & - \\
$\mathrm{M}_{\mathrm{g}}+\mathrm{H}_{\mathrm{r}}$ & 31 & - \\
Hernandina (H') & - & 14.7 \\
Nova (N') & - & 16.6 \\
\hline
\end{tabular}

${ }^{\text {a }}$ The first six samples. Codes in Table 7.

${ }^{\mathrm{b}}$ The last two samples, included for comparison purposes.

${ }^{\mathrm{c}}$ To obtain a Brix to acid ratio of 16 in the final blend. 
Table 9. Descriptive profile of six blended juices and of two pure juices of Hernandina and Nova. Summary results of ANOVA by attribute.

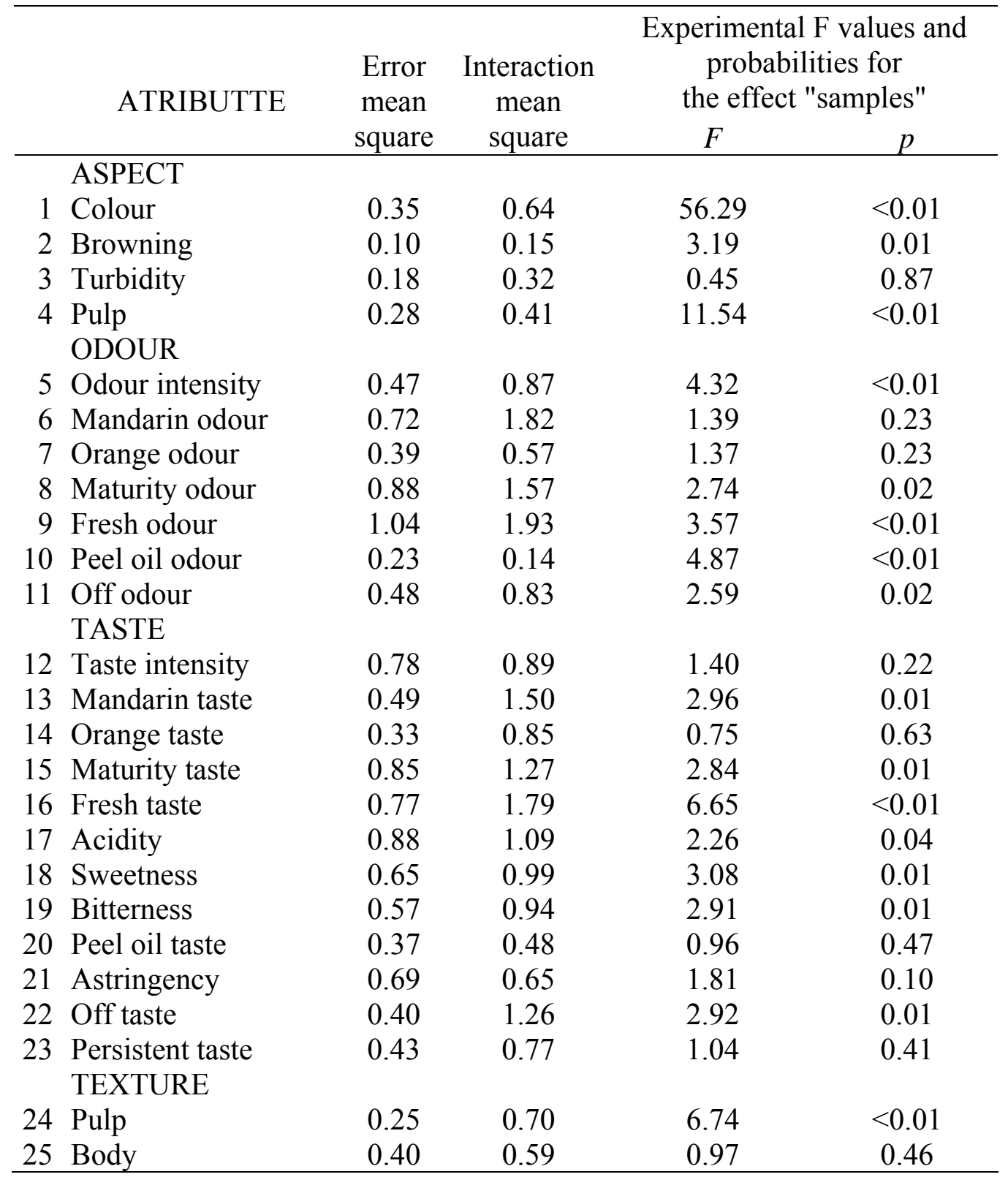


Table 10. Sensory profile of 6 blended juices and of two pure juices of Hernandina and Nova. Mean intensity scores of attributes and minimum significant differences (MSD) between means (Tukey's test, level 95\%).

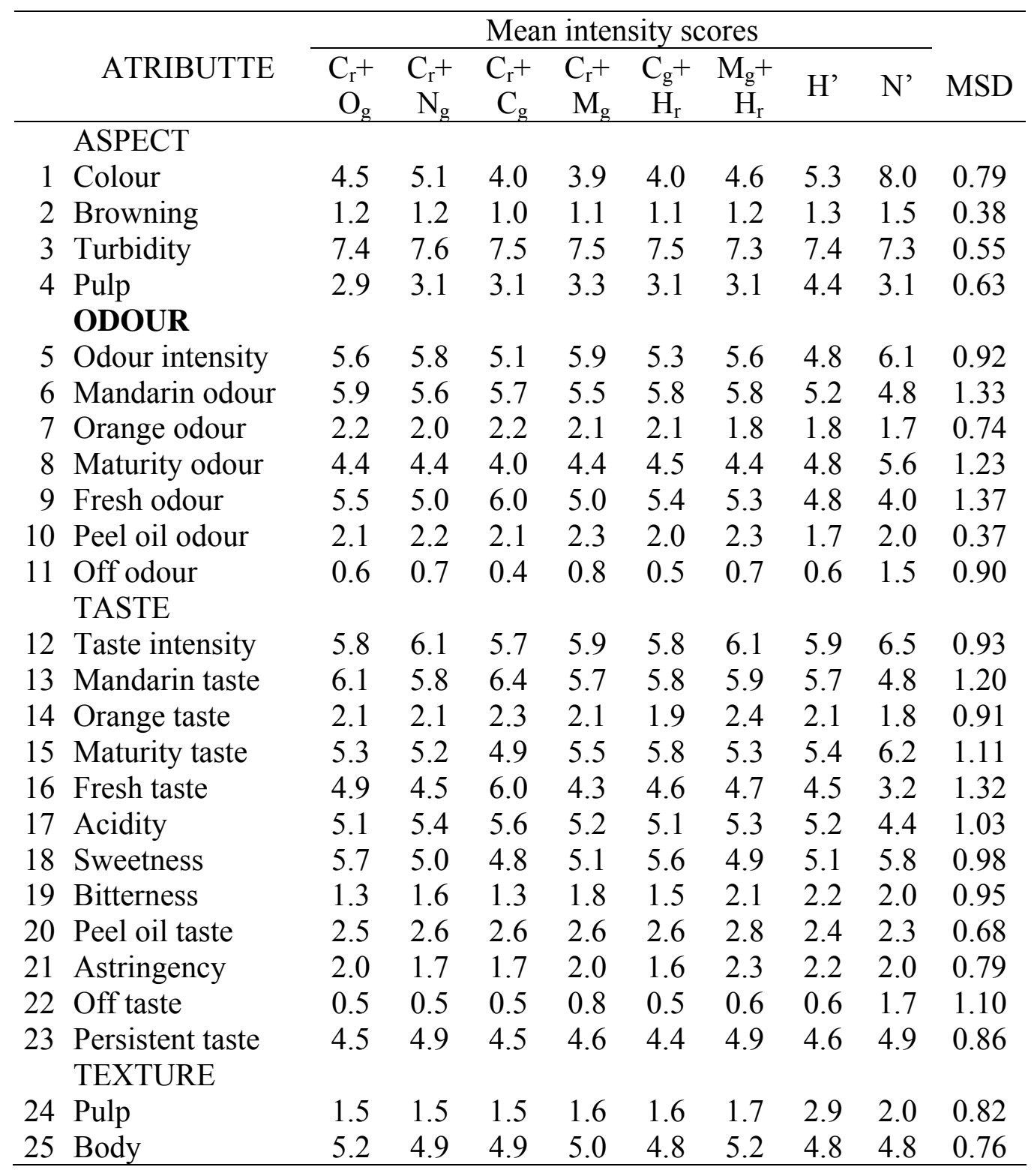


Table 11. Acceptability data of blends converted in rank order numbers: Rank sums.

\begin{tabular}{ll}
\hline \multicolumn{2}{c}{ Samples Rank sums } \\
\hline $\mathrm{C}_{\mathrm{r}}+\mathrm{O}_{\mathrm{g}}$ & $573.0^{\mathrm{a}}$ \\
$\mathrm{Cr}+\mathrm{N}_{\mathrm{g}}$ & $539.0^{\mathrm{a}}$ \\
$\mathrm{C}_{\mathrm{r}}+\mathrm{C}_{\mathrm{g}}$ & $523.5^{\mathrm{a}}$ \\
$\mathrm{C}_{\mathrm{r}}+\mathrm{M}_{\mathrm{g}}$ & $486.5^{\mathrm{a}, \mathrm{b}}$ \\
$\mathrm{C}_{\mathrm{g}}+\mathrm{H}_{\mathrm{r}}$ & $456.5^{\mathrm{b}, \mathrm{c}}$ \\
$\mathrm{H}^{\prime}$ & $420.5^{\mathrm{c}}$ \\
$\mathrm{M}_{\mathrm{g}}+\mathrm{H}_{\mathrm{r}}$ & $387.5^{\mathrm{c}}$ \\
$\mathrm{N}^{\prime}$ & $213.5^{\mathrm{d}}$ \\
\hline
\end{tabular}

Samples that do not significantly differ share the same letter. 
Table 12. Mean acceptability scores by consumers' segments obtained from correlations between consumers and attributes of data from blends. Significance (95\% level) of the differences between means according to Tukey's test

\begin{tabular}{lcccc}
\hline Samples & $\begin{array}{c}\text { Segment 1 } \\
(25 \text { consumers) }\end{array}$ & $\begin{array}{c}\text { Segment2 } \\
(38 \text { consumers })\end{array}$ & $\begin{array}{c}\text { Segment3 } \\
(20 \text { consumers })\end{array}$ & $\begin{array}{c}\text { Segment 4 } \\
(17 \text { consumers })\end{array}$ \\
\hline $\mathrm{C}_{\mathrm{r}}+\mathrm{O}_{\mathrm{g}}$ & $6.0^{\mathrm{a}}$ & $7.0^{\mathrm{a}, \mathrm{b}}$ & $7.1^{\mathrm{a}}$ & $6.8^{\mathrm{a}}$ \\
$\mathrm{C}_{\mathrm{r}}+\mathrm{Ng}$ & $6.1^{\mathrm{a}}$ & $6.3^{\mathrm{b}, \mathrm{c}}$ & $7.1^{\mathrm{a}}$ & $6.5^{\mathrm{a}, \mathrm{b}}$ \\
$\mathrm{Cr}+\mathrm{C}_{\mathrm{g}}$ & $6.2^{\mathrm{a}}$ & $7.3^{\mathrm{a}}$ & $5.6^{\mathrm{b}}$ & $4.9^{\mathrm{b}}$ \\
$\mathrm{C}_{\mathrm{r}}+\mathrm{M}_{\mathrm{g}}$ & $5.4^{\mathrm{a}, \mathrm{b}}$ & $6.3^{\mathrm{b}, \mathrm{c}}$ & $6.2^{\mathrm{a}, \mathrm{b}}$ & $6.3^{\mathrm{a}, \mathrm{b}}$ \\
$\mathrm{C}_{\mathrm{g}}+\mathrm{H}_{\mathrm{r}}$ & $4.6^{\mathrm{b}}$ & $6.4^{\mathrm{b}}$ & $6.3^{\mathrm{a}, \mathrm{b}}$ & $5.2^{\mathrm{a}, \mathrm{b}}$ \\
$\mathrm{H}^{\prime}$ & $6.4^{\mathrm{a}}$ & $5.0^{\mathrm{d}}$ & $4.0^{\mathrm{c}}$ & $5.7^{\mathrm{a}, \mathrm{b}}$ \\
$\mathrm{M}_{\mathrm{g}}+\mathrm{H}_{\mathrm{r}}$ & $5.5^{\mathrm{a}, \mathrm{b}}$ & $5.5^{\mathrm{c}, \mathrm{d}}$ & $5.4^{\mathrm{b}}$ & $5.5^{\mathrm{a}, \mathrm{b}}$ \\
$\mathrm{N}^{\prime}$ & $2.8^{\mathrm{c}}$ & $2.8^{\mathrm{e}}$ & $4.2^{\mathrm{c}}$ & $6.1^{\mathrm{a}, \mathrm{b}}$ \\
\hline
\end{tabular}

In each column, samples that do not significantly differ share the same letter. 


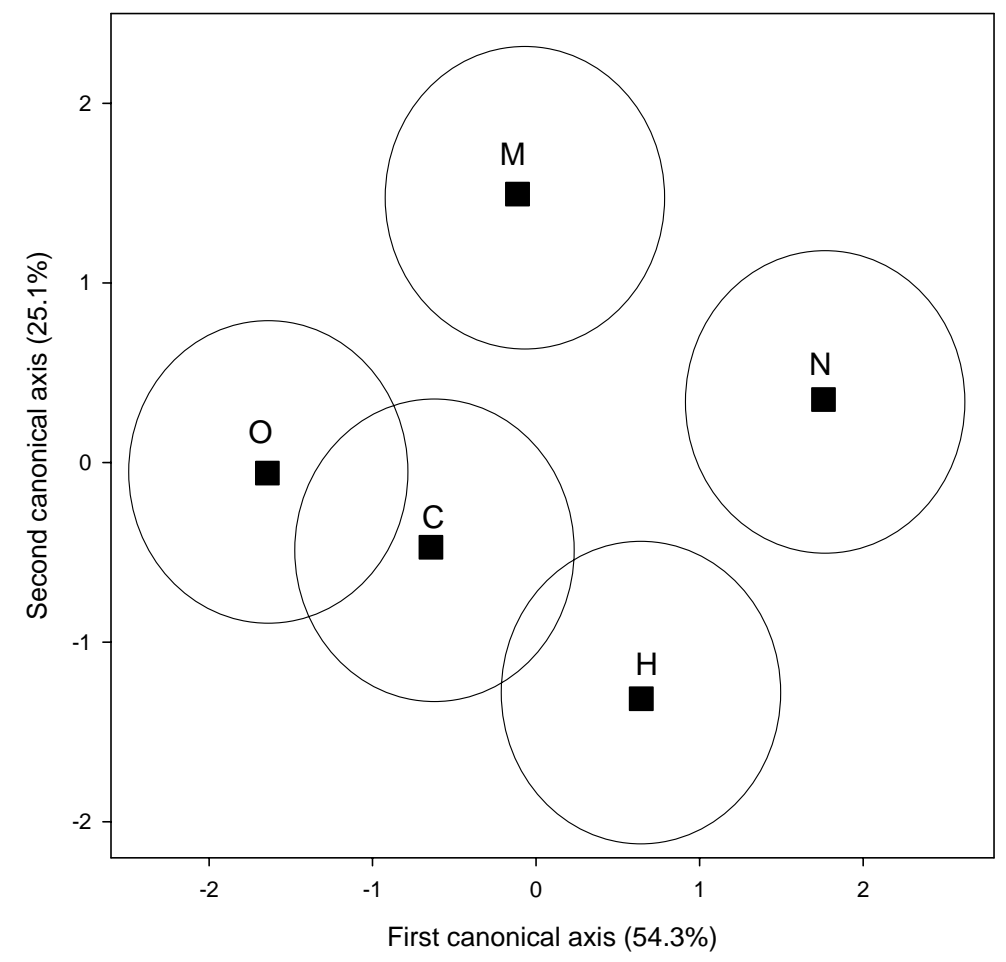

Figure 1. Representation of juices from individual varieties according to results of Canonical analysis applied to data of six sensory attributes with maximum discriminant power. Sample codes in Table 1. 


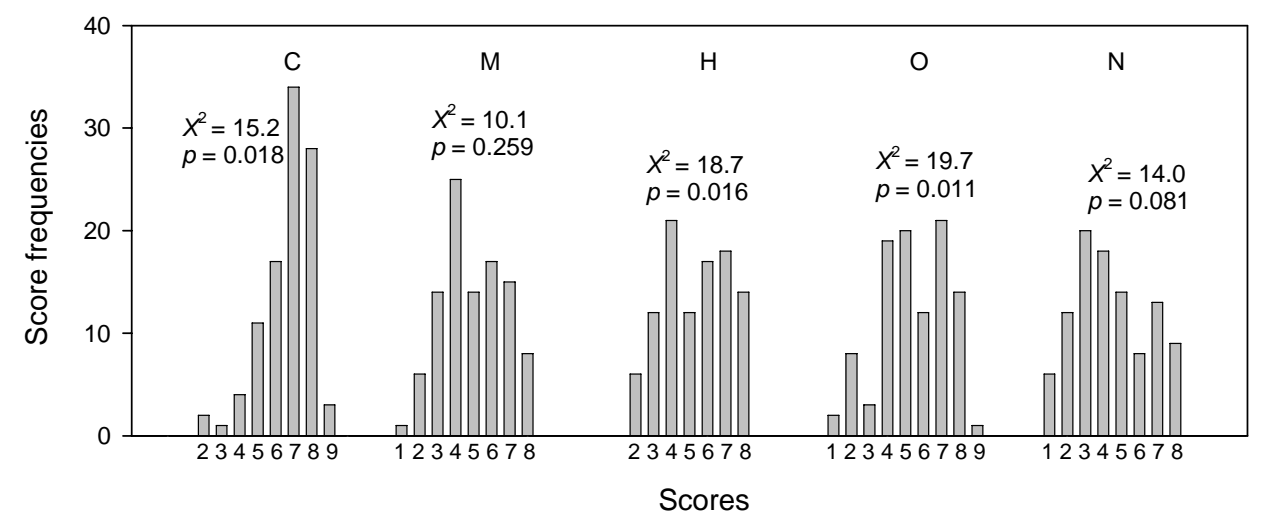

Figure 2. Frequencies of acceptability scores (integer values from 1 to 9) given by 100 consumers to fresh juices from individual varieties. Chi-square values of Pearson test to check the fit of the observed frequencies to the normal distribution. Sample codes in Table 1. 


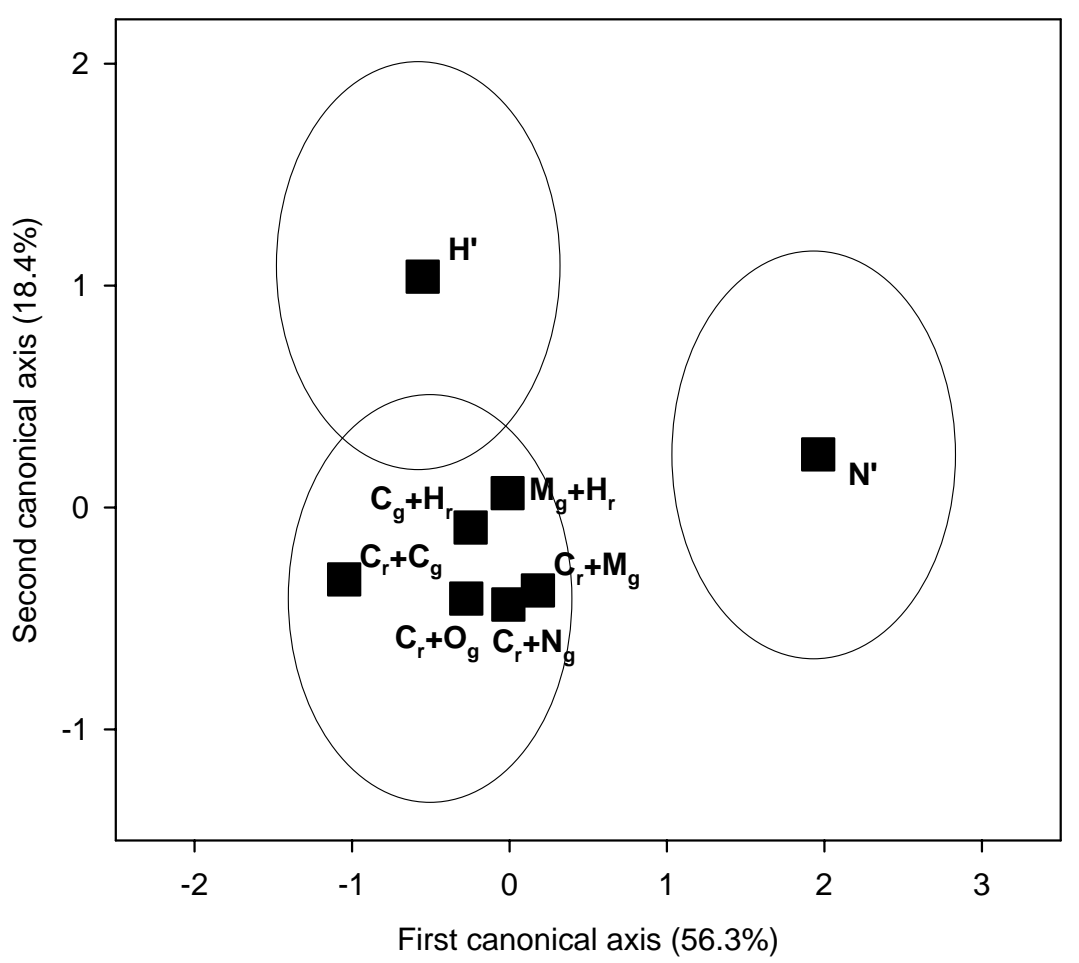

Figure 3. Representation of blends according to results of Canonical analysis applied to data of six sensory attributes with maximum discriminant power. Sample codes in Table 8. 


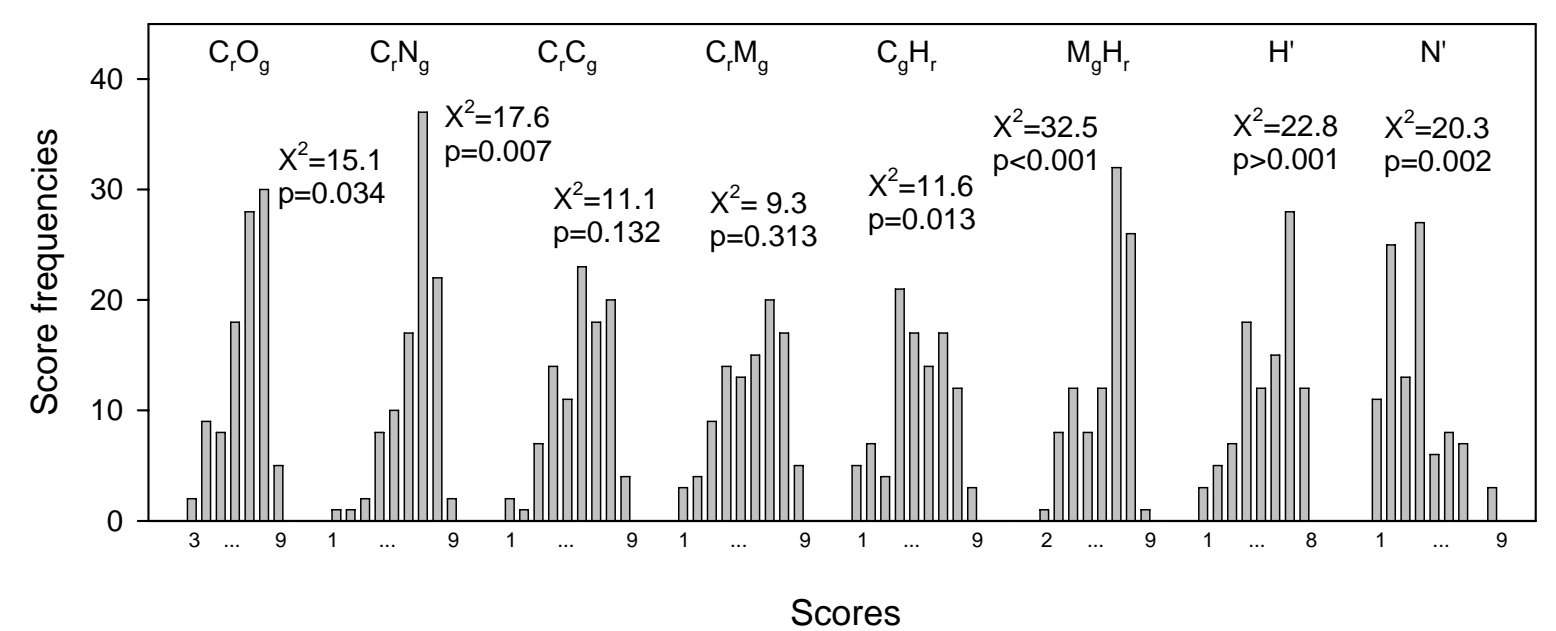

Figure 4. Frequencies of acceptability scores (integer values from 1 to 9) given by 100 consumers to blends. Chi-square values of Pearson test to check the fit of the observed frequencies to the normal distribution. Sample codes in Table 8. 